\title{
Hand model of the brain training as emotion regulation method for elementary school students
}

\section{Pelatihan hand model of the brain sebagai metode regulasi emosi untuk siswa sekolah dasar}

\author{
Lita Patricia Lunanta' ${ }^{1}$, Reneta Kristiani², Aurelia Ardani² \\ 'Departemen Psikologi, Fakultas Psikologi, Universitas Esa Unggul \\ J. Arjuna Utara No.9, Jakarta, 11510, Indonesia \\ ${ }^{2}$ Departemen Psikologi, Fakultas Psikologi, UNIKA Atma Jaya \\ Jl. Jenderal Sudirman No.51, Jakarta, 12930, Indonesia
}

\author{
ARTICLE INFO \\ Received: 2021-03-20 \\ Revised: 2021-05-05 \\ Accepted: 2021-07-07 \\ Keywords: \\ COVID-19, Emotion \\ regulation method, \\ Hand model of the \\ brain
}

\section{ABSTRACT}

In the era of the COVID-19 pandemic, learning from home comes with positive and negative consequences. The sense of security that children get from distance learning brings negative consequences where children need to adjust to a new paradigm. Problems around learning from home included mental health and emotional problems for students. This psychoeducation aimed to explain the emotion regulation process and how the brain worked in emotion processing. We conducted the program with a pre-survey and interviews with teachers and school principals. Furthermore, online mentoring and surveys to students accompanied by their parents. It is hoped that students could understand their emotions and basic steps to regulate. Hand model of the brain is the model of the brain in hands to explain concretely the hierarchy and connection between different parts of the brain concerning emotions. This program got a positive response from the participants. Psychoeducation results show an increase of understanding and gave positive feedback that this program is effective and fit to what they needed.

(C)2021 Published by University of Merdeka Malang. This is an open access article distributed under the CC BY-SA 4.0 license (https://creativecommons.org/licenses/by-sa/4.0/)

How to cite: Lunanta, L. P., Kristiani, R., \& Ardani, A. (2021). Hand Model of Brain Training as Emotion Regulation Method for Elementary School Students. Abdimas: Jurnal Pengabdian Masyarakat Universitas Merdeka Malang, 6(4), 552-564. https://doi.org/10.26905/abdimas.v6i4.5602

\section{PENDAHULUAN}

Pandemi COVID-19 mengharuskan anak untuk belajar dari rumah. Harapannya anak bisa mendapatkan materi atau pembelajaran dengan aman. Pembelajaran daring memang baru dan belum pernah dilakukan sebelumnya, sehingga dibutuhkan adaptasi oleh anak dan orang tua. Mirisnya, beberapa orang tua tidak dapat beradaptasi dengan baik terhadap perubahan metode pembelajaran ini. Seorang ibu di Lebak Banten menganiaya anak kandungnya sampai tewas dengan alasan korban tidak belajar dengan serius selama pembelajaran daring (DetikNews, 2020). Tidak hanya orang tua, pelajar juga mengalami kesulitan dalam beradaptasi dengan pembelajaran daring. Dari berita BBC dikabarkan beberapa pelajar 
mengaku merasa stres, mudah marah, hingga melakukan tindakan bunuh diri (Wijaya, 2021). Lia, seorang pelajar SMP dari Gowa, Sulawesi Selatan mengaku merasa stres. la mengatakan bahwa ia tidak mau melakukan apa-apa dan tidak peduli lagi dengan nilainya yang jatuh semenjak pembelajaran daring.

Lia bukan satu-satunya anak yang merasakan kesulitan beradaptasi dengan metode pembelajaran daring. Berdasarkan survei di bulan Juli 2020 yang dilakukan oleh Kementerian Pemberdayaan Perempuan dan Perlindungan Anak (KPPPA) pada lebih dari 3.200 anak SD hingga SMA mengenai pembelajaran daring, sebanyak $13 \%$ responden mengatakan bahwa mereka mengalami gejala-gejala gangguan depresi ringan hingga berat (Wijaya, 2021). Emosi yang sering mereka rasakan adalah sedih dan mudah marah, sedangkan sebanyak 93\% responden menunjukkan gejala depresi berada pada rentang 1418 tahun, dan 7\% di rentang usia 10-13 tahun. Seorang anak di Maluku juga mengeluhkan sulitnya pembelajaran menggunakan internet, apalagi dengan jaringan yang tidak bagus (Wijaya, 2021). KPAl pada tahun 2020 mencatat seorang siswa kelas XII di Kabupaten Tangerang mengalami depresi hingga harus dirujuk ke rumah sakit. Seorang siswa MTs, Tarakan, Kalimantan Utara bahkan melakukan bunuh diri akibat depresi pada bulan Oktober, 2020 (Wijaya, 2021).

Berdasarkan evaluasi yang dilakukan oleh Kepala Dinas Pendidikan DKI Jakarta (dalam Wijaya, 2020), pembelajaran jarak jauh memberikan dampak negatif maupun positif bagi siswa selama pandemi COVID-19. Terdapat enam dampak negatif dari pembelajaran jarak jauh, yaitu: (1) Ancaman putus sekolah karena beberapa siswa terpaksa membantu perekonomian keluarganya; (2) Penurunan capaian belajar akibat perbedaan akses di antara siswa dan kualitas pembelajaran; (3) Karena tidak dapat pergi ke sekolah, beberapa anak berpotensi menjadi korban kekerasan rumah tangga saat tidak diketahui oleh guru; (4) Keterbatasan memiliki gawai dan kuota internet juga menjadi salah satu dampak negatif dari pembelajaran jarak jauh; (5) Anak lebih sulit menghasilkan capaian akademik yang baik dibandingkan saat pembelajaran tatap muka; dan (6) Anak menjadi kurang bersosialisasi.

Selain dampak negatif dalam pencapaian akademis anak dan adanya potensi kekerasan dalam rumah tangga, pembelajaran jarak jauh memberikan dampak negatif pada keadaan psikologis anak. Menurut Lyly Puspa Palupi, Staf Sub-bagian Psikologi Instalasi Rehabilitasi Medik RSUP Sanglah Denpasar (Hendra, 2020), selain timbulnya rasa bosan pada anak akibat aktivitas di rumah saja, anak juga dituntut beradaptasi untuk belajar dari rumah sehingga hal-hal seperti ini bisa menimbulkan kondisi tertekan pada psikis anak dan berpotensi munculnya stres pada anak. Beberapa anak kesulitan belajar di rumah secara daring karena membutuhkan penjelasan secara langsung oleh guru. Lyly juga menjelaskan bahwa anak menjadi kurang mandiri dan kurang percaya diri akibat tidak dapat bersosialisasi dengan teman sebayanya (Hendra, 2020).

Penelitian menunjukkan bahwa keadaan psikologis anak dapat memburuk berkaitan dengan pembelajaran dari rumah. Sebuah penelitian menemukan bahwa skor stres pasca-trauma empat kali lebih tinggi pada anak-anak yang dikarantina dibandingkan pada mereka yang tidak di karantina (Wang et al., 2020; Sprang \& Silman, 2013). Selain itu, perubahan gaya hidup dan stres psikososial akibat dikarantina di rumah dapat semakin memperburuk kesehatan fisik dan mental sang anak yang nantinya sulit membaik jika tidak segera diatasi. Keadaan psikologis dan gejolaknya dapat diatasi dengan proses regulasi emosi. 
ABDIMAS: Jurnal Pengabdian Masyarakat Universitas Merdeka Malang Volume 6, No. 4, November 2021: 552-564

Menurut Snyder (2005), regulasi emosi adalah suatu proses eksplorasi akan semua potensi adaptif manusia untuk mengenali, memahami, dan mengekspresikan emosi dalam situasi stres. Dalam coping stres yang fokus pada emosi, tujuan utama dari psikoterapi yang dilakukan adalah bagaimana emosi itu dapat dihargai. Dalam pandangan ini, perkembangan manusia yang sukses adalah ekspresi emosi yang seimbang, yaitu emosi dikenali, dipahami, dan dikomunikasikan secara tepat. Dengan ekspresi emosi yang seimbang diharapkan nantinya akan terjadi pengurangan stres. Terapi emosi seperti ini tidak hanya terfokus kepada ekspresi emosi apa adanya tetapi proses emosional dan cara berekspresi yang bisa membantu individu, misalnya dengan mengatur arousal, meningkatkan pemahaman diri, mengembangkan keterampilan pemecahan masalah, dan memperbaiki hubungan interpersonal.

Menurut Dr. Daniel Siegel, seorang pakar interpersonal neurobiology, ada hubungan yang saling berkaitan antara pikiran, otak, dan relasi personal. Sistem limbik merupakan bagian otak yang mengatur emosi manusia. Pada sistem limbik, amygdala memegang kunci pusat rasa takut dan cemas di otak. Perubahan pada perkembangan amygdala di masa kanak-kanak memegang peranan penting dalam perkembangan masalah emosi, terutama kecemasan. Penelitian dari Stanford University School of Medicine pada 76 anak dari rentang usia 7 hingga 9 tahun menyatakan dari hasil MRI (Magnetic Resonance Imaging) pada struktur dan fungsi otak, tampak bahwa anak-anak dengan tingkat kecemasan yang tinggi memiliki ukuran amygdala yang lebih besar daripada anak-anak lainnya. Selain itu, terlihat pula adanya hubungan yang erat antara bagian otak yang berkaitan dengan atensi, persepsi emosi dan regulasi pada anak-anak yang memiliki tingkat kecemasan tinggi (Qin et al., 2014)

Daniel Siegel (Siegel, 2019; Fredrickson \& Siegel, 2018; Siegel \& Bryson, 2013; Siegel, 2012a; Siegel, 2012b; Barton, 2009; Lorenz, 2009; Chessick, 2007) mengembangkan suatu model untuk membantu anakanak memahami emosi dan kinerja otak mereka. Melalui pemahaman cara kerja otak akan membantu anak-anak lebih terbuka menjelaskan apa yang sedang terjadi, terkait emosi mereka, lebih memahami pengalaman yang lalu dan dapat membangun kembali relasi dan rasa percaya mereka dengan orang yang mereka sayangi. Dalam Hand Model of Brain, Siegel menjelaskan bagaimana anatomi tangan bisa mewakili penggambaran terhadap anatomi otak. Jika kita menempatkan ibu jari di tengah telapak dan menutupnya dengan jari-jari lain, anatomi yang didapatkan menyerupai otak. Bagian buku-buku jari adalah bagian depan/wajah sedangkan bagian punggung tangan adalah bagian belakang kepala, sedangkan pergelangan mewakili posisi sumsum tulang belakang. Posisi ibu jari ditekuk kira-kira sama dengan posisi sistem limbik di otak, sedangkan jari-jari yang menutupinya melambangkan posisi area cortex pada otak. Oleh karena itu, penting untuk mengenalkan cara kerja otak pada anak-anak usia 6 hingga 10 tahun agar anak-anak lebih memahami apa yang sedang terjadi di otak mereka. Pemahaman akan cara kerja otak dalam mengatur emosi ini merupakan langkah awal untuk regulasi emosi sehingga anak-anak semakin terampil dalam mengendalikan emosi.

Gehart (2012) mengembangkan model komprehensif untuk mengajarkan mindfulness dan latihan nafas kepada individu, pasangan dan keluarga dengan tujuan memberikan psikoedukasi yang dapat dilakukan sehari-hari secara praktis. Mengacu kepada aktivitas yang dilatihkan oleh Gehart (2012) sebagai bagian dari psikoedukasi, program pengabdian masyarakat yang kami kembangkan ini juga bertujuan untuk memberikan cara praktis kepada anak sekolah dasar untuk memahami cara kerja otak yang rumit yang kemudian dapat mereka gunakan dalam mengenali dan mengendalikan emosi yang dirasakan. 


\section{METODE}

Pengabdian masyarakat dilakukan secara daring melalui media Zoom Video Conference sehingga partisipan berada di lokasi masing-masing. Partisipan adalah seluruh siswa-siswi TK hingga kelas 5 SD dengan rentang usia 5 hingga 10 tahun dari Sekolah Kristen Antar Bangsa yang terdiri atas 18 siswasiswi, 7 guru, dan 1 orang Kepala Sekolah Kristen Antar Bangsa serta 18 orang tua sebagai pendamping. Orang tua dan guru juga diikutsertakan agar mereka dapat turut mengulangi dan melatihkan kembali materi pembelajaran yang sudah diajarkan kepada anak-anak.

Pra-survei dilakukan dengan melakukan wawancara kepada kepala sekolah dan guru. Dari wawancara yang dilakukan tergambar adanya beberapa masalah dalam regulasi emosi siswa, antara lain mudah kehilangan kendali atas emosi ketika diajak berkomunikasi mengenai hasil belajar, mudah gelisah bila menemui kesulitan atau tantangan dalam materi pembelajaran, serta rasa khawatir akan situasi pandemi yang dihadapi ke depannya. Berdasarkan keluhan dan masalah yang ada, fasilitator ingin memberikan psikoedukasi dan pelatihan regulasi emosi dengan memperkenalkan Hand Model of Brain. Metode ini memberikan pengetahuan kepada siswa-siswi mengenai cara kerja emosi terhadap otak mereka dan bagaimana mereka dapat mengendalikannya. Metode ini diharapkan memberikan rasa pemberdayaan kepada siswa, baik dalam hal pengetahuan maupun dalam hal keterampilan regulasi emosi. Program ini dibagi menjadi beberapa tahap dengan jadwal yang berbeda-beda.

\section{Tahap inisiasi}

Tahap inisiasi dilakukan ketika fasilitator berdiskusi dengan pihak mitra mengenai permasalahan yang dihadapi siswa-siswi sehari-hari. Tujuan tahap ini adalah untuk menggali masalah sehingga fasilitator dapat menerapkan program yang sesuai dengan kebutuhan mitra. Tahap inisiasi dilakukan pada awal Januari 2021

\section{Tahap persiapan kegiatan}

Dalam tahap persiapan, fasilitator berusaha menyederhanakan penjelasan cara kerja otak dan emosi kepada anak usia Taman Kanak-Kanak dan Sekolah Dasar. Hand Model of Brain dinilai cukup sederhana untuk membuat siswa-siswi bisa memahami mekanisme yang terjadi pada otak mereka, terutama ketika mereka sedang mengalami kecemasan atau sedang tidak tenang secara emosi. Tahap persiapan meliputi proses penyusunan materi presentasi, proses penyusunan pre-test dan post-test, penyusunan evaluasi kegiatan, serta pembuatan alat bantu yang akan digunakan untuk menjelaskan model otak dan pengaruh emosi pada otak dan pemilihan metode relaksasi yang sesuai dengan usia partisipan. Tahap persiapan kegiatan dilakukan pada bulan Januari 2021, dari tanggal 15-30 Januari 2021.

\section{Tahap pelaksanaan program}

Pelaksanaan program kegiatan dilakukan pada tanggal 4 Februari 2021 dari pukul 13.00-15.00 WIB dengan satu orang fasilitator utama dan dua orang fasilitator pendamping. Kegiatan dilakukan de- 
ABDIMAS: Jurnal Pengabdian Masyarakat Universitas Merdeka Malang

Volume 6, No. 4, November 2021: 552-564

ngan tahapan sebagai berikut.

Tahap pembukaan. Sebelum memulai kegiatan, fasilitator memperkenalkan diri dan juga mencoba mengenal para partisipan. Hal ini dilakukan untuk membangkitkan suasana yang akrab dan saling mengenal. Setelah itu, fasilitator mengajak partisipan mengisi pre-test materi pengenalan emosi yang dibagikan melalui Google Form. Sebagai awal kegiatan, fasilitator menggunakan kegiatan ice breaking secara virtual dan daring. Hal ini dilakukan untuk membangun suasana santai dan membantu partisipan memusatkan perhatian kepada kegiatan.

Tahap penyampaian isi/materi. Metode presentasi digunakan untuk menjelaskan materi yang hendak dibagikan kepada partisipan. Metode presentasi dilakukan secara daring dengan menggunakan aplikasi Zoom Meeting yang dimiliki oleh sekolah. Presentasi dilakukan secara interaktif dengan partisipan boleh memotong kapan saja mereka ingin penjelasan tambahan serta fasilitator bertanya secara aktif kepada partisipan untuk meminta keterlibatan mereka. Metode praktik dilakukan agar partisipan mengaplikasikan secara langsung penjelasan yang didapatkan dari presentasi. Metode praktik terutama untuk meyakinkan fasilitator bahwa partisipan memahami model kerja otak secara sederhana dan bagaimana mereka bisa memahaminya lewat bantuan model otak pada tangan (Hand Model of Brain). Fasilitator juga menggunakan alat peraga berupa glitter jar untuk menjelaskan pengaruh emosi terhadap proses berpikir. Yang terakhir, praktik yang dilakukan bersama berkaitan dengan penerapan metode relaksasi dengan latihan pernafasan.

Tapan penutup. Fasilitator menyimpulkan kembali hal-hal yang sudah dipelajari dan dilatihkan oleh partisipan serta memastikan semua partisipan memahami dan mampu melakukan hal-hal yang sudah diberikan pada psikoedukasi ini.

\section{Tahap evaluasi program}

Evaluasi program dilakukan dengan mengisi post-test dan melakukan evaluasi kegiatan menggunakan pertanyaan-pertanyaan yang diisi partisipan melalui Google Form. Fasilitator kemudian membandingkan hasil post-test dan pre-test yang ada serta menyimpulkan penilaian yang diberikan partisipan dari evaluasi yang diberikan.

\section{HASIL DAN PEMBAHASAN}

Kegiatan psikoedukasi pengenalan model otak kepada anak sekolah dasar berlangsung dengan baik dari awal hingga selesai. Partisipan aktif mengikuti setiap tahap kegiatan dengan respons aktif secara verbal dan motivasi untuk mencoba menjawab pertanyaan yang diberikan. Partisipan juga mempraktikkan hal-hal yang dipresentasikan dan menyempurnakan hasil praktiknya sesuai dengan arahan fasilitator.

\section{Hasil kegiatan}

Pelaksanaan kegiatan dapat dibagi menjadi tiga bagian. Tahap pembukaan adalah ketika partisipan mengisi/mengerjakan pre-test yang berkaitan dengan emosi untuk melihat pengetahuan awal 
mereka mengenai keterkaitan antara emosi dan tubuh mereka. Tahap kedua adalah tahap pelaksanaan yang meliputi ice breaking, presentasi materi, serta praktik penguasaan Hand Model of Brain dan praktik relaksasi pernafasan. Tahap ketiga adalah tahap evaluasi di mana partisipan mengisi post-test yang memiliki pertanyaan yang sama dengan pre-test untuk melihat apakah ada penambahan pengetahuan atau tidak. Tahap akhir juga meliputi evaluasi pelaksanaan kegiatan yang diberikan oleh partisipan kepada fasilitator dan materi yang diberikan.

Tahap isi adalah ketika fasilitator memberikan dan mempraktikkan materi yang diberikan kepada partisipan. Beberapa hal yang terjadi pada tahap kedua antara lain: (1) Sebagai awal kegiatan, fasilitator menggunakan kegiatan ice breaking secara virtual dan daring (Teachers Pay Teachers, 2020). Dalam kegiatan ini, partisipan diminta untuk melakukan beberapa kegiatan fisik dalam waktu 3 menit. Pada Gambar 1, terlihat bahwa kegiatan yang terpilih untuk dilakukan tampil secara acak pada layar presentasi. Hal ini dimaksudkan untuk mencairkan suasana serta membangun kesan yang positif terhadap kegiatan yang akan dilakukan; (2) Metode presentasi digunakan untuk menjelaskan materi yang hendak dibagikan kepada partisipan. Metode presentasi dilakukan secara daring dengan menggunakan aplikasi Zoom Meeting yang dimiliki oleh sekolah. Presentasi dilakukan secara interaktif dengan partisipan boleh memotong kapan saja mereka ingin penjelasan tambahan serta fasilitator bertanya secara aktif kepada partisipan untuk meminta keterlibatan mereka. Presentasi dilakukan untuk menjelaskan pertama-tama mengenai bagaimana emosi bisa dikenali lewat tanda-tanda fisik yang terjadi pada tubuh. Partisipan diajak untuk menganalisis setiap tanda-tanda fisik dan kemudian menentukan emosi yang berkaitan dengan tanda-tanda fisik tersebut. Partisipan diajak untuk memberikan nama kepada emosi yang mereka rasakan merujuk kepada daftar emosi seperti pada Gambar 2. (Changing Minds, 2021; Human Diseases and Conditions, 2020; Dunn, 2019; Hoffman, 2013).

Kemudian, presentasi dilanjutkan untuk menjelaskan mengenai cara kerja otak dalam memproses emosi serta menanggapi stimulus yang datang dari lingkungan atau dari dalam dirinya. Cara kerja otak ini dijelaskan dengan alat peraga dan dipraktikkan langsung oleh partisipan. Pertama-tama, fasilitator menjelaskan bahwa untuk memahami otak secara sederhana, dapat digunakan pembagian yang dikemukakan oleh Paul MacLean mengenai Triune Brain, (Gambar 3), yaitu bahwa otak bisa dibagi menjadi tiga bagian besar, antara lain reptilian brain, emotional/mamalian brain, dan thinking/human brain (MacLean, 2019; Thebrain.mcgill.ca, 2014; Maclean, 1985).
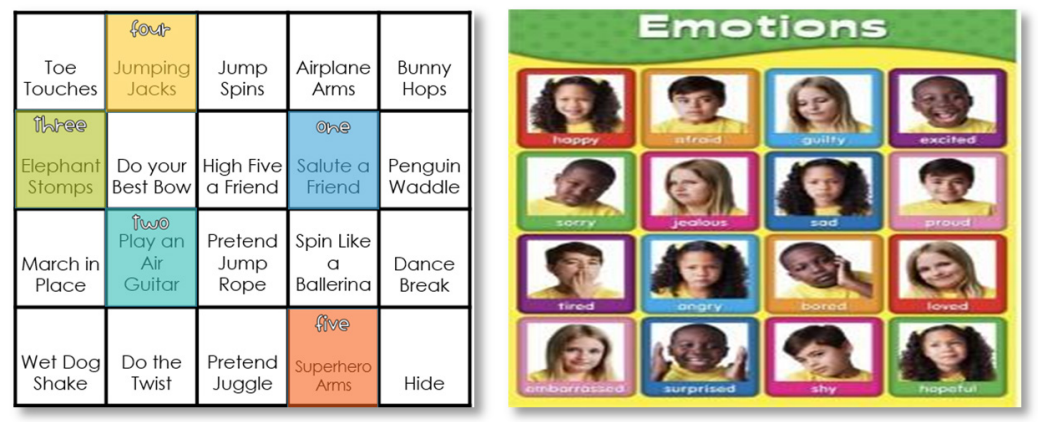

The Three-Parted Brain

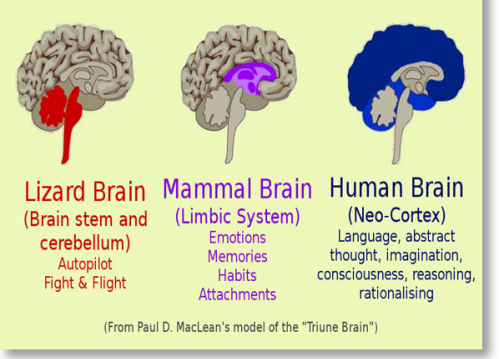

Gambar 1. Digital brain breaks (Sumber: https://www.teacherspayteachers.com)

Gambar 2. Macam-macam emosi (Sumber: https://www.koolandchild.com)

Gambar 3. Triune brain (Sumber: https://yourownbestfriend.co.uk/triune-brain/) 
ABDIMAS: Jurnal Pengabdian Masyarakat Universitas Merdeka Malang Volume 6, No. 4, November 2021: 552-564

Penjelasan kemudian dilanjutkan bagaimana proses sederhana (Gambar 4) ketika suatu stimulus diterima oleh otak dan diproses menjadi emosi dan akhirnya menghasilkan suatu perilaku atau reaksi tertentu.

Setelah menjelaskan mengenai kerja otak dengan alat peraga, fasilitator menjelaskan mengenai hal-hal yang dapat dilakukan untuk membantu meregulasi emosi yang dirasakan, mulai dari mengenali emosi tersebut, kemudian membantu menganalisis hal-hal yang partisipan butuhkan untuk meregulasi emosinya. Beberapa kebutuhan yang kemungkinan berkaitan dengan regulasi emosi, antara lain kebutuhan untuk afeksi, kebutuhan untuk mendapatkan perhatian, kebutuhan untuk dimengerti atau didengarkan, kebutuhan untuk apresiasi, serta kebutuhan untuk istirahat. Partisipan diajarkan bagaimana bagian thinking part dari otak mereka bisa berkomunikasi kepada bagian emotional part dari otak mereka untuk bisa memenangkan diri. Penjelasan ini menggunakan model otak pada tangan (Hand Model of Brain) dari Dr. Daniel Siegel seperti yang dicontohkan pada Gambar 5 (Nelson et al., 2014)
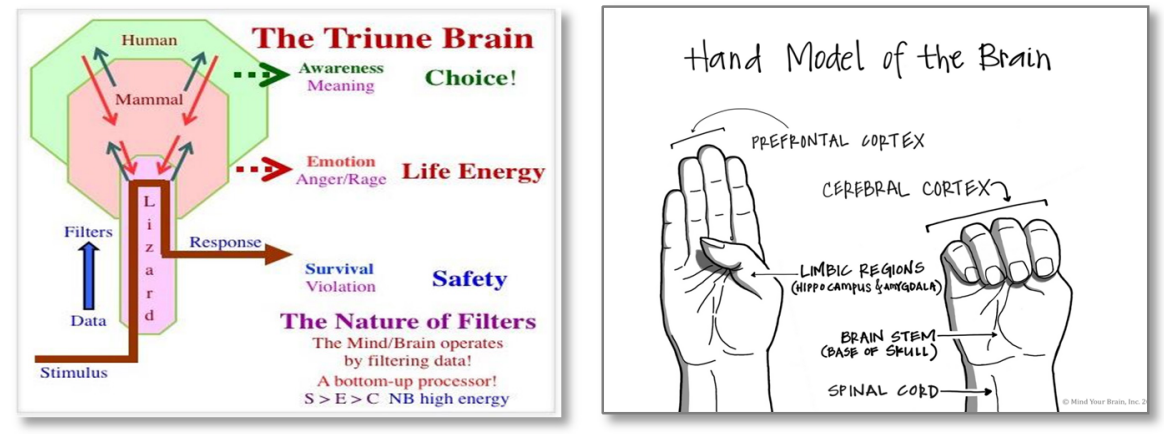

Gambar 4. Penjelasan triune brain (Sumber: thehumansideofglobalwarming.com) Gambar 5. Hand Model of Brain (Sumber: https://madeleinesiegel.org/lllustration)

Presentasi ditutup dengan menjelaskan apa yang terjadi ketika emosi tidak bisa dikendalikan. Emosi mempengaruhi seluruh kerja otak sehingga tidak dapat berpikir dengan jernih. Pada Gambar 6 terlihat bagaimana emosi bisa diumpamakan sebagai glitter yang membuat air menjadi keruh, dilanjutkan dengan penjelasan bagaimana mereka bisa mengambil kendali kembali terhadap situasi ini, yaitu dengan menggunakan thinking brain mereka, yaitu berpikir secara logis.
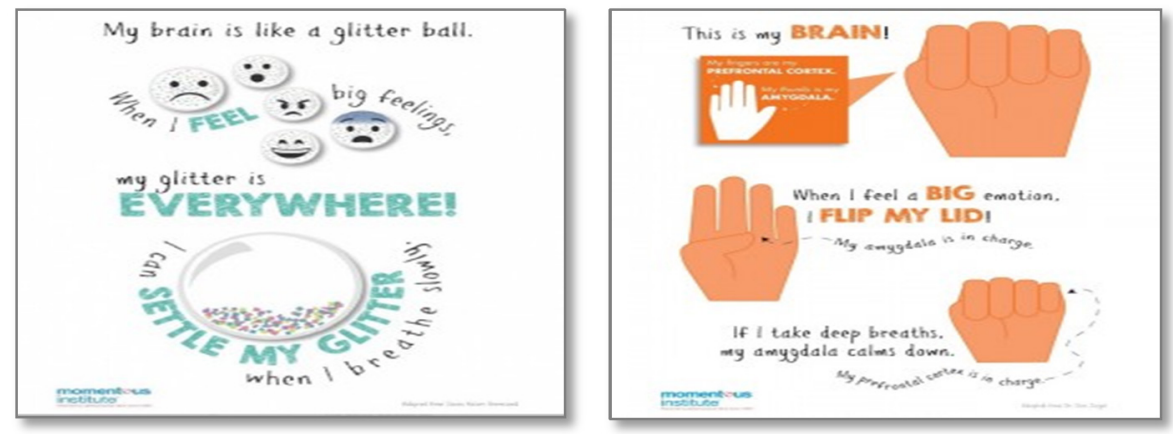

Gambar 6. Penjelasan otak yang emosional (Sumber: https://momentousinstitute.org) 
Berpikir secara logis tidak dapat dilakukan ketika emosi belum diregulasi. Fasilitator menjelaskan tahap-tahap yang dapat dilakukan untuk fasilitator juga memperkenalkan salah satu metode sederhana untuk menenangkan diri, yaitu dengan teknik pernafasan kotak (square breathing/box breathing), (Gambar 9) yaitu teknik pernafasan dengan hitungan yang teratur, 4 hitungan untuk menarik nafas, 4 hitungan menahan nafas, 4 hitungan mengeluarkan nafas, 4 hitungan menahan nafas, 4 hitungan lagi untuk menarik nafas, dan seterusnya. Siklus ini diulangi beberapa kali hingga perasaan menjadi lebih tenang dan terkendali dan partisipan dapat menggunakan pemikiran yang rasional kembali.

Metode praktik dilakukan agar partisipan mengaplikasikan secara langsung penjelasan yang didapatkan dari presentasi. Metode praktik terutama untuk meyakinkan fasilitator bahwa partisipan memahami model kerja otak secara sederhana dan bagaimana mereka bisa memahaminya lewat bantuan model otak pada tangan hand model of the brain. Dengan perbandingan jumlah fasilitator dan jumlah partisipan yang cukup memadai (1:6), masing-masing fasilitator dapat memperhatikan bagaimana tiap partisipan mempraktikkan pemahamannya terhadap model kerja otak ini.

Fasilitator menggunakan bantuan boneka jari binatang mamalia (Gambar 7) untuk menunjukkan bagaimana ibu jari adalah lokasi dari otak mamalia (mammalian brain) yang menjadi pusat emosi seseorang. Masing-masing partisipan diminta untuk menunjukkan tangannya dan mempraktikkan secara langsung model otak pada tangan mereka. Mereka diminta untuk mengenali bagian-bagian otak dan fungsi dari masing-masing bagian tersebut. Fasilitator bertanya secara acak kepada partisipan untuk memastikan pemahaman mereka.

Praktik kemudian dilanjutkan dengan membahas emosi yang membuat partisipan tidak dapat berpikir, bagaimana perasaan bisa membuat pikiran menjadi tidak jernih. Fasilitator menggunakan glitter jar (Gambar 8) untuk menjelaskan fenomena ini. Ketika partisipan merasakan emosi yang terlalu kuat, hal itu seperti glitter jar yang digoyangkan, pandangan menjadi tidak jernih karena tertutup oleh perasaan yang kuat.
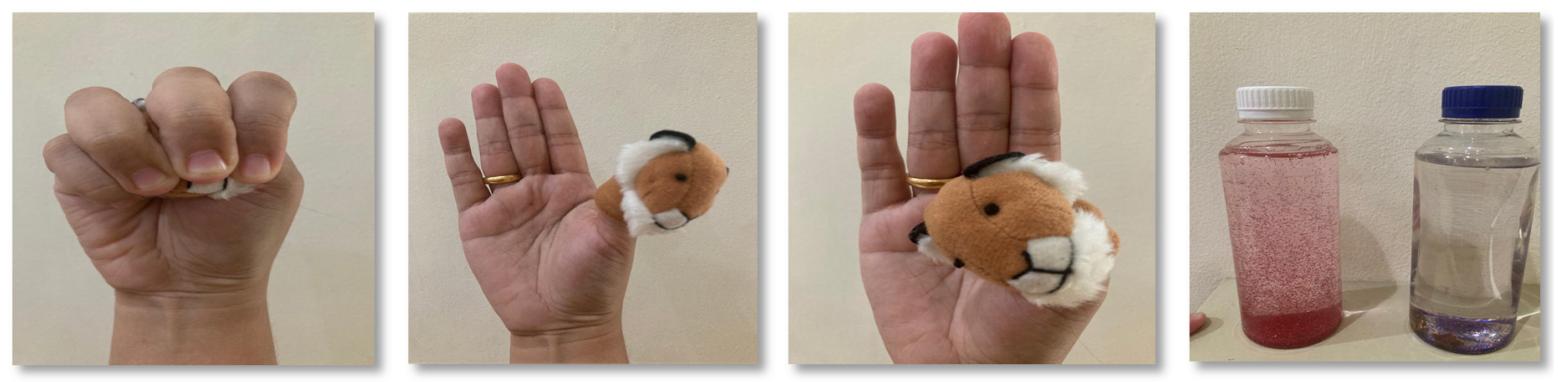

Gambar 7. Alat peraga hand model of the brain

Ketika partisipan mengambil waktu diam sejenak, dalam hal ini dengan mempraktikkan latihan pernafasan box breathing/square breathing (Gambar 9), glitter kembali turun ke dasar wadah, dan semuanya menjadi jelas kembali. Hal ini dilakukan untuk partisipan bisa memahami secara visual, mekanisme yang terjadi dalam otak ketika kita mengambil waktu untuk menenangkan diri. Proses latihan pernafasan pada 
ABDIMAS: Jurnal Pengabdian Masyarakat Universitas Merdeka Malang Volume 6, No. 4, November 2021: 552-564

awalnya tidak mudah dilakukan oleh partisipan sehingga dilakukan pengulangan beberapa kali sampai partisipan merasa cukup menguasai ritme nafas yang diharapkan terjadi. Pada tahap ini, partisipan aktif mengajukan pertanyaan dan berusaha melakukan latihan pernafasan dengan benar.

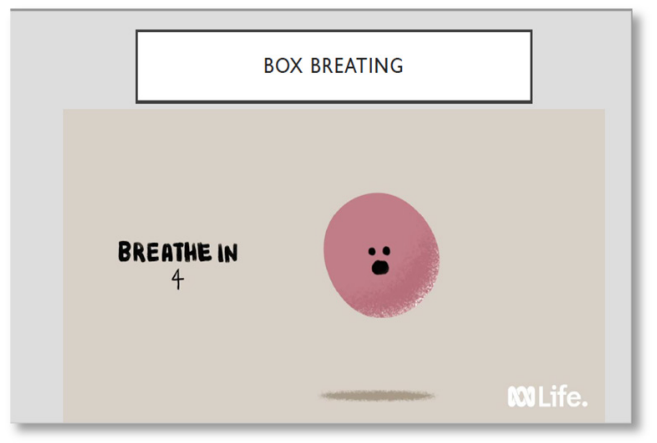

Gambar 9. Box breathing/square breathing (Sumber: https://youtu.be/R3GtOcPmCe4)

Pada tahap penutup yang merupakan tahap akhir, dilakukan post-test kepada partisipan untuk melihat apakah ada penambahan pengetahuan mengenai regulasi emosi dan mengenai cara kerja otak. Pada bagian ini, partisipan juga mengisi lembar evaluasi untuk menilai materi yang telah didapatkan serta melakukan penilaian kepada fasilitator. Pada tahap ini merupakan tahap akhir dari pelaksanaan program pengabdian masyarakat dalam bentuk psikoedukasi ini.

Dalam program pengabdian pada masyarakat ini, materi yang digunakan menyangkut proses regulasi emosi yang meliputi proses pengenalan emosi dan tanda-tanda emosi dalam tubuh. Materi pelatihan yang digunakan kemudian membahas Hand model of Brain dari Daniel Siegel untuk menjelaskan anatomi dan kaitan antara bagian-bagian dalam otak menggunakan alat peraga tangan masing-masing (Siegel, 2012b). Dalam menjelaskan otak, Hand Model of Brain membagi otak ke dalam tiga bagian besar.

Seorang ahli syaraf, Paul D. MacLean memformulasikan model otak ini sekitar tahun 1960, disempurnakan lagi dalam publikasi-publikasi selanjutnya. Model ini memang merupakan penyederhanaan dari aktivitas dan organisasi otak namun memberikan penjelasan yang mudah dimengerti mengenai hierarki dalam fungsi otak. Triune brain membagi otak menjadi 3 bagian utama, yaitu the primitive brain (reptilian complex), the limbic system (paleomammalian complex), dan the new cortex (neomammalian complex).

The primitive brain merupakan bagian yang bertanggung jawab pada pertahanan hidup utama, seperti detak jantung, pernafasan, temperatur tubuh, dan orientasi keseimbangan. Fungsi dari bagian ini akan mengambil alih aktivitas otak lainnya ketika berlawanan dengannya. The limbic system, kadang disebut sebagai otak emosi, merupakan bagian reaktif yang menginisiasi respon "fight" atau "flight" atau "freeze" ketika menghadapi bahaya. Bagian utama yang berkaitan dengan psikoterapi adalah hipokampus, amygdala, dan hipotalamus. Dalam bagian ini terdapat evaluasi bawah sadar dan sistem 
respons yang dirancang untuk menjaga individu dalam keadaan aman. Yang menjadi perhatian dalam psikoterapi adalah bagaimana sistem limbik bisa salah menilai suatu keadaan itu berbahaya atau tidak. The new cortex adalah bagian otak yang pintar, bagian ini bertanggung jawab untuk aktivitas sadar, seperti bahasa, berpikir abstrak, imajinasi, kreativitas, dan lain-lain. Bagian pre-frontal bereaksi lebih lambat terhadap informasi yang masuk tetapi lebih kompleks dan rumit dalam prosesnya. Pada bagian ini, individu dapat berpikir rasional dan logis, kreatif dan bertujuan. Pre-frontal korteks dapat diambil alih oleh sistem limbik ketika ada persepsi adanya ancaman (baik nyata maupun dalam imajinasi).

\section{Pembahasan}

Dalam pelaksanaan program pengabdian dalam bentuk pelatihan ini terdapat beberapa tolak ukur dasar pencapaian dari kegiatan pelatihan. Tolak ukur yang pertama adalah ketika pelaksanaan kegiatan berlangsung sesuai dengan waktu yang sudah ditentukan dan berhasil membahas semua materi yang ada mengenai model otak pada tangan serta aplikasinya untuk regulasi emosi. Tolak ukur yang kedua adalah dalam praktik, ketika partisipan dapat melakukan sesuai dengan yang dicontohkan oleh fasilitator dan dapat digunakan secara praktis dalam proses memahami dan meregulasi emosi. Tolak ukur berikutnya berkaitan dengan hasil post-test yang dikerjakan oleh partisipan dimana ada hasil yang berubah dan meningkat dari pre-test yang sebelumnya mereka kerjakan. Terakhir, tolak ukur keberhasilan mengacu kepada evaluasi yang diberikan partisipan terhadap kegiatan yang dilakukan. Hal ini dapat dilihat dari hasil polling yang dilakukan dari akhir kegiatan. Hasil pre-test partisipan ada pada nilai rata-rata 64 dari range skor 0-100, sedangkan hasil post-test partisipan ada pada nilai rata-rata 80 dari range skor 0-100. Hal ini menunjukkan adanya perubahan dalam pengetahuan yang partisipan miliki mengenai emosi dan bagaimana proses regulasinya.
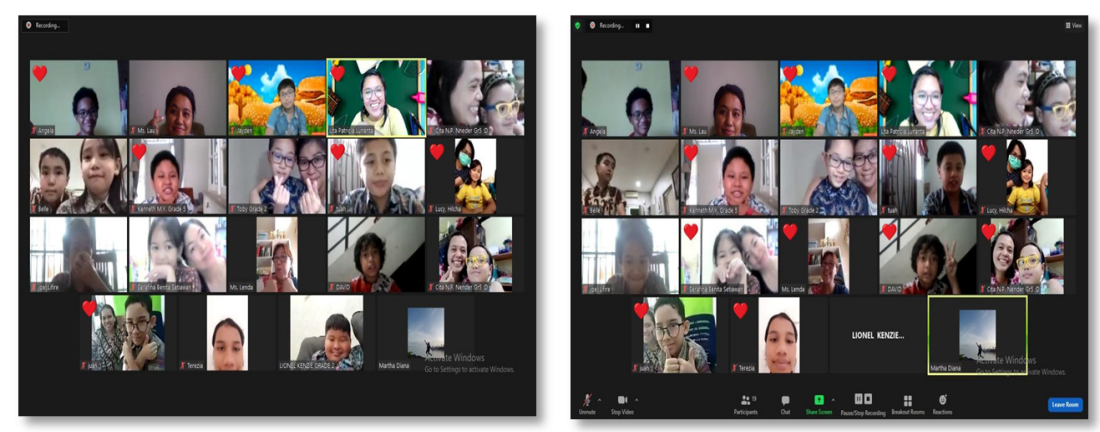

Gambar 10. Partisipan yang aktif sebagai faktor pendukung dalam kegiatan

Partisipan (Gambar 10) mendiskusikan macam-macam gejala pada fisik yang bisa diterjemahkan sebagai macam-macam emosi. Pertanyaan yang diajukan antara lain bagaimana mengatasi emosi tertentu yang muncul secara negatif, terutama rasa bosan dan rasa gelisah selama belajar jarak jauh. Emosi yang muncul dapat diatasi ketika dikenali lebih dulu. Ketika sudah dikenali, barulah emosi negatif dapat diatasi ("name it to tame it'). Partisipan juga mendiskusikan bersama hal-hal apa yang dapat 
ABDIMAS: Jurnal Pengabdian Masyarakat Universitas Merdeka Malang Volume 6, No. 4, November 2021: 552-564

mereka lakukan untuk meredakan emosi negatif serta mempraktikkan teknik pernafasan bersamasama. Setelah edukasi dan praktik yang dilakukan, partisipan melaporkan adanya perasaan yang lebih tenang dan terkendali. Mereka melaporkan ingin memasukkan aktivitas yang dipelajari pada sesi ini untuk proses pembelajaran mereka sehari-hari.

Tabel 1. Evaluasi kegiatan

\begin{tabular}{|c|c|c|c|c|c|}
\hline Evaluasi Kegiatan & $\begin{array}{l}\text { Sangat Tidak } \\
\text { Sesuai (\%) }\end{array}$ & $\begin{array}{l}\text { Tidak Ses- } \\
\text { uai (\%) }\end{array}$ & $\begin{array}{l}\text { Sedang } \\
(\%)\end{array}$ & Sesuai (\%) & $\begin{array}{c}\text { Sanga } \\
\text { Sesuai } \\
\text { (\%) }\end{array}$ \\
\hline Kesesuaian isi materi dengan tujuan & - & - & 9,1 & 27,3 & 63,6 \\
\hline $\begin{array}{l}\text { Tambahan pemahaman dan pengetahuan setelah } \\
\text { kegiatan }\end{array}$ & - & - & - & 27,3 & 72,7 \\
\hline $\begin{array}{l}\text { Efektivitas komunikasi dan kemampuan pemateri } \\
\text { dalam menyampaikan }\end{array}$ & - & 9,1 & 9,1 & 18,2 & 63,6 \\
\hline Penilaian terhadap keseluruhan kegiatan & - & - & - & 9,1 & 90,9 \\
\hline $\begin{array}{l}\text { Kesediaan untuk ikut kegiatan serupa di kemudian } \\
\text { hari }\end{array}$ & - & - & - & - & 100 \\
\hline
\end{tabular}

Dari evaluasi kegiatan yang ditampilkan pada Tabel 1, sebanyak 63,6\% partisipan mengungkapkan isi materi sudah sesuai dengan tujuan. Sebesar $72,7 \%$ partisipan merasa bertambah pemahaman dan pengetahuannya setelah kegiatan. Sebanyak $63,6 \%$ partisipan merasa pemateri sudah efektif dalam melakukan komunikasi. Partisipan menilai 90,9\% keseluruhan kegiatan sangat sesuai dengan kebutuhan mereka. Sebanyak 100\% atau semua partisipan bersedia mengikuti kegiatan serupa di kemudian hari. Dari hal ini dapat disimpulkan bahwa secara umum partisipan merasa puas dengan kegiatan webinar.

\section{SIMPULAN DAN SARAN}

Proses psikoedukasi dan praktik berlangsung dengan lancar dengan partisipan yang aktif serta evaluasi yang cukup positif. Partisipan menunjukkan peningkatan pemahaman lewat perbedaan antara skor pre-test dan post-test yang diperoleh (64 menjadi 80). Dari hasil evaluasi, seluruh partisipan menyatakan ingin mengikuti lagi kegiatan yang serupa serta 90,9\% mengungkapkan bahwa kegiatan ini sangat sesuai dengan yang mereka harapkan. Diharapkan agar psikoedukasi yang sudah dilakukan ini dapat membantu siswa memahami diri sendiri dan dimanfaatkan ketika siswa mengalami tantangan emosi selama belajar jarak jauh. Pengabdian masyarakat yang dilakukan menerapkan satu program psikoedukasi kepada seluruh partisipan tanpa ada kelompok kontrol atau pembanding. Oleh karena itu, indikator keberhasilan psikoedukasi yang dilakukan hanya berdasarkan kepada hasil pre-test dan post-test peningkatan pemahaman dan review kualitatif dari partisipan. Untuk kegiatan berikutnya dapat melibatkan kelompok kontrol dan kelompok yang mendapatkan perlakuan (psikoedukasi dan praktik) untuk mendapatkan indikator keberhasilan yang lebih jelas dan objektif. Selain itu, walaupun kegiatan dilakukan kepada seluruh siswa dan orang tua yang ada di TK B hingga kelas 5 SD, jumlah partisipan hanyalah 18 siswa dan 18 orang tua. Untuk lebih memperluas pengaruh dari psikoedukasi yang dilakukan serta menilai secara lebih objektif efektivitasnya program ini disarankan digunakan 


\section{Hand model of the brain training as emotion regulation method for elementary school students}

Lita Patricia Lunanta, Reneta Kristiani, Aurelia Ardani

untuk sekolah-sekolah lain juga dengan jumlah peserta yang lebih besar sehingga dapat diperoleh hasil yang lebih komprehensif.

Program ini terbukti dapat dilakukan secara daring, tetapi akan lebih baikjika dapat dilakukan secara langsung. Partisipan dapat lebih terfokus pada materi dan terkontrol dalam mengikuti seminar. Selain itu dengan program secara langsung, fasilitator bisa lebih berinteraksi dengan partisipan serta leluasa berekspresi dalam menyampaikan materinya. Untuk melihat bagaimana pengenalan emosi lewat model hand brain dapat berpengaruh kepada kelompok usia lain, program ini juga dapat dilakukan kepada kelompok usia lain, misalnya pada remaja untuk lebih memahami gejolak emosi yang mereka rasakan dalam masa pertumbuhan, atau pada orang tua untuk memahami diri sendiri dan kemudian memahami juga apa yang anak-anak alami dalam kesehatan mental. Secara praktis, sekolah juga disarankan untuk menggunakan pengetahuan mengenai emosi ini untuk dapat mengenali masalah-masalah emosi yang dirasakan siswa serta menjadikan teknik regulasi emosi bagian dari proses pembelajaran sehari-hari.

\section{DAFTAR PUSTAKA}

Barton, D. (2009). The mindful brain: Reflection and attunement in the cultivation of well-being. The Journal of Clinical Psychiatry, 70(3). https://doi.org/10.4088/jcp.08bk40888

Changing Minds. (2021). Emotional body language. Changing Minds. http://changingminds.org/techniques/body/emotional_body.htm

Chessick, C. (2007). Review of the mindful brain: Reflection and attunement in the cultivation of wellbeing. The American Journal of Psychiatry, 164(10), 1619-1620. https://doi.org/10.1176/appi.ajp.2007.07081292

DetikNews. (2020, September 20). Miris, bocah SD tewas di tangan orang tua gara-gara susah belajar online. DetikNews. https://news.detik.com/berita-jawa-barat/d-5180315/miris-bocah-sdtewas-di-tangan-orang tua-gara-gara-susah-belajar-online

Dunn, K. T. (2019, Januari 15). Body clues activities: Emotional expression and identification for anxious kids. Compassionate Counseling. https://www.compassionatecounselingstl.com/blog/ emotional-expression-activity-identification-for-kids

Fredrickson, B. L., \& Siegel, D. J. (2018). Broaden-and-build theory meets interpersonal neurobiology as a lens on compassion and positivity resonance. In Compassion (203-217). Routledge. https://doi.org/10.4324/9781315564296-12

Gehart D.R. (2012) Teaching mindfulness practice in therapy. in Mindfulness and acceptance in couple and family therapy. Boston: Springer. https://doi.org/10.1007/978-1-4614-3033-9_6

Hendra. (14 Oktober 2020). Ini dampak negatif belajar via daring menurut psikolog dan cara mengatasinya. Redaksi 24. https://www.redaksi24.com/ini-dampak-negatif-belajar-viadaring-menurut-psikolog-dan-cara-mengatasinya/

Hoffman. (2013). Feelings list. Hoffman. https://www.hoffmaninstitute.org/wp-content/uploads/ Practices-FeelingsSensations.pdf

Human Diseases and Conditions. (2020). Emotions. Human diseases and conditions. http://www. humanillnesses.com/Behavioral-Health-Br-Fe/Emotions.html 
ABDIMAS: Jurnal Pengabdian Masyarakat Universitas Merdeka Malang

Volume 6, No. 4, November 2021: 552-564

Lorenz, S. (2009). The mindful brain: Reflection and attunement in the cultivation of well-being. Journal of Mental Health, 18(2). https://doi.org/10.1080/09638230802523096

MacLean, P. (2019). A triune concept of the brain and behaviour. University of Toronto Press. https://doi.org/10.3138/9781487576752

Maclean, P. D. (1985). Evolutionary psychiatry and the triune brain. Psychological Medicine, 15(2), 219221. https://doi.org/10.1017/S0033291700023485

Nelson, B. W., Parker, S. C., \& Siegel, D. J. (2013). Interpersonal neurobiology, mindsight, and integration. Infant and early childhood mental health: Core concepts and clinical practice, 129.

Qin, S., Young, C. B., Duan, X., Chen, T., Supekar, K., \& Menon, V. (2014). Amygdala subregional structure and intrinsic functional connectivity predicts individual differences in anxiety during early childhood. Biological Psychiatry, 75(11), 892-900.

https://doi.org/10.1016/j.biopsych.2013.10.006

Siegel, D. J. (2012a). Mind, brain, and relationships: The interpersonal neurobiology perspective. The developing mind: How relationships and the brain interact to shape who we are, 1-45.

Siegel, D. J. (2012b). Pocket guide to interpersonal neurobiology: An integrative handbook of the mind (Norton series on interpersonal neurobiology). WW Norton \& Company.

Siegel, D. J. (2019). The mind in psychotherapy: An interpersonal neurobiology framework for understanding and cultivating mental health. Psychology and Psychotherapy: Theory, Research and Practice, 92(2), 224-237. https://doi.org/10.1111/papt.12228

Siegel, D. J., \& Bryson, T. P. (2013). The whole-brain child: 12 revolutionary strategies to nurture your child's developing mind. Australia: Scribe Publications.

Snyder, C. R., \& Lopez, S. J. (2005). Handbook of positive psychology. New York: Oxford University Press.

Sprang, G., \& Silman, M. (2013). Posttraumatic stress disorder in parents and youth after healthrelated disasters. Disaster medicine and public health preparedness, 7(1), 105-110. https://doi.org/10.1017/dmp.2013.22

Teachers Pay Teachers. (2020). Digital brain breaks [PowerPoint slides]. Teachers Pay Teachers. https:// www.teacherspayteachers.com/Product/Digital-Brain-Breaks-for-Self-Regulation-DuringDistance-Learning-5673809

Thebrain.mcgill.ca. (2014). The brain from top to bottom. In Thebrain.Mcgill.Ca.

Wang, G., Zhang, Y., Zhao, J., Zhang, J., \& Jiang, F. (2020). Mitigate the effects of home confinement on children during the COVID-19 outbreak. The Lancet, 395(10228), 945-947. https://doi.org/10.1016/S0140-6736(20)30547-X

Wijaya, C. (18 Februari 2021). Covid-19: "Stres, mudah marah, hingga dugaan bunuh diri", persoalan mental murid selama sekolah dari rumah. BBC News Indonesia. https://www.bbc.com/indonesia/indonesia-55992502

Wijaya, L. D. (1 Oktober 2020). Dampak negatif dan positif pembelajaran jarak jauh selama pandemi Covid-19. Tempo.co. https://metro.tempo.co/read/1391861/dampak-negatif-dan-positifpembelajaran-jarak-jauh-selama-pandemi-covid-19 